\title{
Social and Educational Challenges regarding the Promotion of Higher Education in Pakistan: An Analytical Study
}

\author{
KHUDA BAKHSH \\ 1*Department of Education, GC University Faisalabad, PAKISTAN. \\ SAFIA NIAZI \\ Department of Education, Benazir Bhutto University, Karachi, PAKISTAN. \\ MUHAMMAD HAFEEZ \\ Research Scholar, Allama Iqbal Open University, Islamabad, PAKISTAN. \\ SAFDAR HUSSAIN TAHIR \\ Director Lyallpur Business School, GC University, Faisalabad, PAKISTAN.
}

\begin{abstract}
Every nation has social aims which are belongs to their ideology. Education is one of the powerful source by which the real concept of ideology can be determined. This paper discusses the importance and need of the implementation and awareness of higher education in northern areas of Pakistan in order to bring attention from government sector to raise the budget and take economic measures to build educational institutions at graduate and post graduate level in order to globalize with the communities. The overall strategy of this study is quantitative and survey based. A total of 250 teachers were selected from 10 educational institutions of northern areas out of whole by random sampling. For data collection, a structured questionnaire based on "Likert Scale" containing 20 items served as the instrument of the study. Five hypotheses were made to evaluate results. The collected data were analyzed quantitatively using Correlation, Regression and Anova to explore the nonexistence economic condition of northern educational system. Results and findings suggested that the educational system of northern areas strongly need the surety of developed universities, sound economic opportunities and awareness regarding gender discrimination, skilled and trained instructors and administration, technological advancement to promote higher education system in northern areas of Pakistan.
\end{abstract}

Key Words: Environment, Development, Education and Environment, Education and Development, Challenges.

Received: May 22, 2021. Revised: September 14, 2021. Accepted: October 10, 2021. Published: October $25,2021$.

\section{Introduction}

Pakistan, officially known as the "Islamic Republic of Pakistan" and appeared on the map on 14 August, 1947. It covers an area of about $796,096 \mathrm{~km}^{2}$ and shares its borders with China, India, Iran and Afghanistan. The Location of Pakistan has vital importance in South Asia. It connects the Eastern world with the West. Before partition of the subContinent, the state of Jammu and Kashmir with a total area of 84471 square miles was geographically divided into following three big regions namely "Jammu Province, Kashmir Province and Frontier Province of Ladakh and Gilgit." "In 1947, a part of the state gained independence and was called Azad Jammu and Kashmir, which has an area of 5,134 square miles. While 29,814 square miles' chunk of the Frontier Province of Ladakh and Gilgit after winning freedom came under the administrative control of Pakistan through an agreement. This is the area now called Northern Areas. The rest of the Frontier province i.e., 3,3740 sq. miles' area of Ladakh is under Indian occupation [1-2]. The
Northern Areas of Pakistan are source of global attraction for their heights and vast ranges of $\mathrm{K}-2$, Hindukush, Pamir and the Himalayas. While establishing the constitutional future of the Northern Areas, the full bench of the Azad Kashmir High Court held in a petition filed by Mohammad Miskeen and Haji Bashir Khan of Gilgit and Shaikh Abdul Aziz Advocate from Muzaffarabad. Northern Areas (Gilgit and Baltistan) are part of Azad Kashmir, historically and constitutionally [3-4]. The purpose of conducting this study were (i) To explore the key causes of the underground realities and aptitudes towards unavailable opportunities regarding deficiency of higher education (ii) To observe the political and economic reformation factors regarding the quality of undergraduate education (iii) To examine the shortage of higher educational institutes in northern areas of Pakistan (iv) To deliberate the educational and traditional approaches of the native people of northern areas of Pakistan. 


\section{Literature Review}

The Education Sector of Pakistan suffers from insufficient financial input, low levels of efficiency for implementation of programs, and poor quality of management, monitoring, supervision and teaching. With a per capita income of over $\$ 450$ Pakistan has an adult literacy rate of $49 \%$, while both Vietnam and India with less per capita income have literacy rates of $94 \%$ and $52 \%$, respectively Literacy is higher in urban areas and in the provinces of Sindh and Punjab, among the higher income group, and in males [5-7]. In Northern Areas as in the rest of Pakistan teaching is a poorly paid profession, which is not highly regarded by the local communities. In order to improve the status of teachers and the quality of teaching and learning both the government and the Aga Khan Education Service in the Northern Areas began to train hundreds of teachers through their Field Based Teacher Development Programmed (FBTDP) which was initiated by the Aga Khan Education Service in Pakistan in the early 1980s [89]. The Aga Khan Education Service, Pakistan is a nongovernmental organization (NGO), which owns and manages 123 primary and secondary schools, mainly in the Gilgit and Ghizer districts. Although they were set up primarily for the education of girls, they have more recently become coeducational. Parents generally prefer to send their children to these schools because their medium is English, unlike the government schools where the medium of instruction is Urdu. Other NGOs such as the Naunehal and Hunza Education Resource Project (HERP) as well as many private and army institutions complement the government provision for schooling [10-12]. When it comes to upgrade the level of higher education like any other country the policy makers and educationist of Pakistan also want to promote post graduate education in whole country. At post graduate level the universities in Pakistan have status and complete unconventionality to work with their own terms and conditions. After independence in 1972, National Education Commission suggested to University Grants Commission to oversee Universities according to national and international standards but the achievement of desired goal did not accomplish completely. In April 2001 the new task force comprised on 17 members known as Higher Education Commission was taking the charge and gave their best of services in order to build an ideal scenario. Condition of Education at Graduate Level in Northern Areas of Pakistan [13]. In 1981 the literacy rate in Gilgit Baltistan was only $3 \%$, it was gradually increased in to $37.85 \%$ in 1998 [14]. Pakistan's overall literacy rate remains static at 58 percent with literacy rate of males 70 percent and 48 percent of females, as due to the Population and Housing Census, the Pakistan Social and Living Standards Measurement was not carried out for 201718. According to the Pakistan Economic Survey, 2017-2018, the literacy rate for entire Pakistan, includes ten years old and above is 58 percent [1516]. A better education system can enhance the social, scientific, and technological improvement of a country. The human resource development of a country depends upon the quality of education imparted in country [17]. Higher education is admittedly a separate stage quite distinct from primary, secondary, elementary, and higher secondary stage [18]. The people in Pakistan and South Asia are neither deficient in talent nor in moral qualities in comparison to any other nation of the world, but about two centuries of foreign rule and blind imitation of western attitudes and methods, unsuited to the genius and spiritual conditions of its people, have spoiled some of the virtues and have brought a bad name to their intellectual capacities [19]. Fishkin [20] observed that Pakistan is unfortunately really regressive in education as in certain other spheres of intellectual activities but luckily people are not inherently incompetent. It is however necessary that the diagnosis about difficulties should be correct and the measures for curing these disorders should be appropriate in the light of that diagnosis. In the context of this era of globalization the international relationships like industry, trade, education, politics and economic reformation can be extending in a positive manner. It helps to solve the social problems of the society all over the world to promote global culture naturally. The role of globalization is to motivate people of different countries with dissimilar cultures for work together and closer to each other. In this regard the northern areas of Pakistan do not have sufficient facilities and latest technology to deal globally. Rural areas still deprived from colleges. The division of urban areas has colleges with a very small number, which are only intermediate. Recently only one university was established in the whole province called Karakoram International University but still it needs more faculty and administrative staff to enrich the departments. When it comes to discuss about the educational boards in the whole province only two boards are working in this large populated area Peshawar Board and Abbottabad Board. Peshawar board possesses only technical education and do not deal with medical courses, which is the main reason of its low credibility. On the other hand, Abbottabad Board is famous and acceptable in province (KPK) because of the association of medical field. Higher education is a service since it exhibits all the classical features of services: it is intangible and 
heterogeneous, meets the criterion of inseparability by being produced and consumed at the same time, satisfies the perishability criterion and assumes the students' participation in the delivery process [21]. Athiyainan [22] highlighted that "higher education institutions seeking to assess quality must first identify the institutional characteristics that are most valued by its clients and then measure the clients' perception of the institution performance against these characteristics. This raises the issue of who is the customer in education. According to Dilshad [23] educational institutions have many customers: students, staff, faculty, alumni, donors, and others. Memon [24] claimed that the university views the students as their primary customers who receive the educational services, parents as customers who pay for their children's education, corporations as customers who hire the students, and faculty members as customers who teach students the knowledge needed to perform the job.

Quality indicators can be defined into three main categories: input, processes and output. Output consists of knowledge, skills and values which are gained by student [25]. In Reba and Afridi [26], perceptions on quality of teacher education is taken in these aspects: learning aids/ technology, curriculum, admissions, teaching and learning processes, evaluation procedures, teaching practice and research activities. West et al [27] A superb university education was recognized regarding 13 inputs to the framework, methodology and results. Topics to rise included adjusting toward oneself, superb college scholastics, advancement and examination, at times with an unequivocal connection to arrangement for passage into the workforce. Recommendations concerning how quality in advanced education could be guaranteed in a worldwide economy incorporated two wide subjects - more correspondence in the middle of bosses and colleges from one viewpoint and markers of accomplishment on the other. But even if we assume certain global forces impact on higher education, like mystification neo-liberal politics, or ICT, they are not uniform but multidimensional. They develop in a world of un-simultaneity that will not be affected to the same extent and at the same point in time. Yet, it should be possible, even as we might note that the global spread of standardized educational models, to perceive persistent peculiarities of higher education systems and distinct national options [28].

\section{Hypotheses}

$\mathrm{H}_{1}$ : The non-existence availability of Higher education institutions effect promotion of higher education in northern areas of Pakistan.
$\mathrm{H}_{2}$ : Unstable economic conditions effect promotion of higher education in northern areas of Pakistan.

$\mathrm{H}_{3}$ : Education means effect promotion of higher education in northern areas of Pakistan.

$\mathrm{H}_{4}$ : Deficiency of organized Planning for education effects promotion of higher education in northern areas of Pakistan.

$\mathrm{H}_{5}$ : Traditional approaches of local people's effect globalization and promotion of higher education in northern areas of Pakistan.

\section{Study Methodology}

This research is an empirical quantitative study, exploring the existing attribute and condition of higher education in northern areas of Pakistan to globalize. Primary data used in this study. Five Point Likert scale questionnaire consists of twenty statements with three options is the research tool. In this study Promotion of higher education in Northern areas of Pakistan is the dependent variable and nonexistence availability of higher education institutions unstable economic condition, educational means in Northern areas, organized planning for education, and traditional approaches of people of Northern Areas are the independent variables. The population of this study comprised on two hundred and fifty teachers which have been selected through random sampling out of whole population. Following Government and Private sector educational institutions of northern areas were selected for the purpose of data collection. Government High School Bahadura, Government High School Ladarmang, Al Rahmania Public School and Technical College Gandaf, Ali Polytechnic School and College Haripur, Government Girls Degree College Sarai Saleh, Peace Group of College Abbottabad, Ripahah International University Islamabad, Government Boys High School and Colleges, Government High School Hassan Baa, Government High School Chandore.

\section{Study Results}

\subsection{Model Equation}

Promote higher education in Northern area of Pakistan $=$ constant + Nonexistence availability of education institutions+ Unstable economic condition of northern areas of Pakistan + Educational means in Northern areas + unorganized Planning for education+ Traditional Approach of people of Northern areas. The model form is,

$$
\begin{gathered}
\text { PHE }=\beta_{0}+\beta_{1}(\mathrm{NEA})+\beta_{2}(\mathrm{UEC})+\beta_{3}(\mathrm{EM})+\beta_{4}(\mathrm{OP}) \\
+\beta_{5}(\mathrm{TA})+\mathrm{u}_{\mathrm{t}}
\end{gathered}
$$


Where intercept term is $\beta_{0}$ and regression coefficients are $\beta_{1}, \beta_{2}, \beta_{3}, \beta_{4}$, and $\beta_{5}, \mathrm{u}_{\mathrm{t}}$ indicates the stochastic disturbance term where $\mathrm{t}$ shows the $\mathrm{t}^{\text {th }}$ time.

\subsection{Analysis of Results}

SPSS 16, Descriptive statistics, Correlation and Multiple regression model are used to analyze the results of this research.

\subsection{Descriptive Statistics}

Table 1 shows that 60 percent male and 40 percent female out of 250 samples filling the questionnaire of this research.

\subsection{Reliability Statistics}

Cronbach's Alpha shows the reliability of data or questionnaire and for the reliable data the value of alpha should be equal to or more than 0.7 is acceptable. In this research the value of Cronbach's Alpha for six items is 0.833 , which shows that data is reliable and suitable for use in this research.

Table.1: Gender Frequency Percentage out of 250 samples

\begin{tabular}{|l|c|c|c|}
\hline \multicolumn{1}{|c|}{ Gender } & Frequency & Percentage & Cumulative Frequency \\
\hline Male & 150 & 60 & 60 \\
\hline Female & 100 & 40 & 100 \\
\hline Total & 250 & 100 & $-\cdots-$ \\
\hline
\end{tabular}

Table 2: Reliability of data through Cronbach's Alpha

\begin{tabular}{|l|l|}
\hline Cronbach`s Alpha & No. of Items \\
\hline 0.833 & 6 \\
\hline
\end{tabular}

Table.3: Correlation of Dependent and Independent Variables

\begin{tabular}{|c|c|c|c|c|c|c|}
\hline & PHE & NEA & UEC & EM & OP & TA \\
\hline PHP & 1 & & & & & \\
\hline NEA & 0.614 & 1 & & & & \\
\hline UEC & 0.406 & 0.581 & 1 & & & \\
\hline EM & 0.518 & 0.56 & 0.659 & 1 & & \\
\hline UOP & 0.698 & 0.751 & 0.641 & 0.719 & 1 & \\
\hline TA & 0.242 & 0.264 & 0.3 & 0.181 & 0.363 & 1 \\
\hline
\end{tabular}




\subsection{Correlation}

Strength of relationship of dependent and independent variables shows through the Correlation. In this research results of Correlation found that Promote higher education found positively correlation to Nonexistence availability of higher education institutions unstable economic condition of northern areas, Educational means in Northern areas, Organized Planning for education, and Traditional approaches of people of Northern areas.

\subsection{Regression Analysis}

In Model Summary table the value of "R" is .718 which shows the correlation or strength of association is $71.8 \%$ between the independent variables that are Nonexistence availability of educational institutions, unstable economic condition of northern areas, Education in Northern areas, unorganized Planning for education, and Traditional approaches of northern areas and dependent variable which is Promote higher education. R Square is the percentage of the variation on dependent variable due to change in independent variable. The value of $\mathrm{R}$ Square is .516, which shows the $51.6 \%$ variation on dependent variable (Promote higher education) due to change in independent variables (NEA, UEC, EM, OP, TA). Likewise, the value of Durbin Watson involves that no autocorrelation error in data.

\subsection{ANOVA Analysis}

In regression model ANOVA table shows the overall significance of model. The significance value is .000 less than .05, which shows that over all model is significant. The F Value 51.939 shows the combine effect of the model. The degree of freedom shows that the number of independent variables that went into calculating the estimate. In regression, the value of $\mathrm{df}$ is 5 which indicate 5 independent variables that went into calculating the estimate. The value of $\mathrm{df}$ in total that, there are 249 samples and in residual it is 244.

Table.4: Correlation or Strength of Variable Association

\begin{tabular}{|l|l|l|l|l|l|}
\hline \multicolumn{7}{|c|}{ Model Summary } \\
\hline \multicolumn{1}{|c|}{ Model } & \multicolumn{1}{|c|}{$\mathrm{R}$} & $\mathrm{R}$ Square & $\begin{array}{c}\text { Adjusted R } \\
\text { Square }\end{array}$ & $\begin{array}{c}\text { Std. Error of } \\
\text { the Estimate }\end{array}$ & $\begin{array}{c}\text { Durbin- } \\
\text { Watson }\end{array}$ \\
\hline 1 & $0.718^{\mathrm{a}}$ & 0.516 & 0.506 & 0.583 & 0.300 \\
\hline $\begin{array}{l}\text { Predictor Constant : Nonexistence availability of education institutions , unstable economic } \\
\text { condition of northern areas, Educational means in Northern areas, Unorganized Planning for } \\
\text { education, and Traditional approaches. }\end{array}$ \\
\hline
\end{tabular}


Table.5: Significance Value of Variables

\begin{tabular}{|l|l|l|l|l|l|l|}
\hline \multicolumn{7}{|c|}{ ANOVA $^{\mathrm{b}}$} \\
\hline \multirow{2}{*}{ Model } & Sum of Squares & Df & Mean Square & F & Sig. \\
\hline & Regression & 88.269 & 5 & 17.654 & 51.939 & $.000^{\mathrm{a}}$ \\
\cline { 2 - 7 } & Residual & 82.935 & 244 & .340 & & \\
\cline { 2 - 7 } & Total & 171.204 & 249 & & & \\
\hline \multicolumn{7}{|c|}{ Dependent Variable: Promote Higher Education } \\
\hline \multicolumn{7}{|c|}{ Predictors: (Constant), NEA, UEC, EM, OP, TA. } \\
\hline
\end{tabular}

\subsection{Regression Coefficients}

Table 6 found the values and effects of each independent variable (NEA, UEC, LEM, OP, TA) on dependent variable (PHE). The beta of Nonexistence availability of higher institutions is .161, which shows this variable positively impact on PHE (promote higher education in northern areas of Pakistan) and their impact is significant because sig. value is .001 , which is less than $5 \%$. The beta of uncertain economic conditions is -.113 which indicates the negative impact on PHE and impact is significant because the sig. value is .034 , which is less than $5 \%$. The beta of education means is .063 , which shows the positive and insignificant impact on Promotion of higher education in northern areas of Pakistan because their sig. value is .252 , which is greater than $5 \%$. The beta of education means is .063 , which shows the positive and insignificant impact on Promotion of higher education in northern areas of Pakistan because their sig. value is .252 , which is greater than 5\%. The beta of traditional approaches of northern areas is .004 , which shows the positive but insignificant impact on Promote higher education in northern areas of Pakistan. 
Table.6: Values and Effects of each Independent Variable

\begin{tabular}{|c|c|c|c|c|c|c|}
\hline \multirow{2}{*}{\multicolumn{2}{|c|}{ Model }} & \multicolumn{2}{|c|}{ Unstandardized Coefficients } & \multirow{2}{*}{$\begin{array}{c}\begin{array}{c}\text { Standardized } \\
\text { Coefficients }\end{array} \\
\text { Beta }\end{array}$} & \multirow[b]{2}{*}{$\mathrm{T}$} & \multirow[b]{2}{*}{ Sig. } \\
\hline & & B & Std. Error & & & \\
\hline \multirow[t]{6}{*}{1} & (Constant) & 0.500 & 0.092 & & 5.451 & 0.000 \\
\hline & NEA & 0.161 & 0.047 & 0.234 & 3.398 & 0.001 \\
\hline & UEA & -0.113 & 0.053 & -.138 & -2.131 & 0.034 \\
\hline & EM & 0.063 & 0.055 & 0.081 & 1.148 & 0.252 \\
\hline & UOP & 0.427 & 0.066 & 0.550 & 6.519 & 0.000 \\
\hline & TA & 0.004 & 0.027 & 0.008 & 0.163 & 0.870 \\
\hline & & a. Depe & iable: Prom & Higher Educatic & & \\
\hline
\end{tabular}

\subsection{Model Equation}

Promote Higher Education $=(.500)+(.161)$ nonexistence availability of higher institutions +($.113)$ unstable economic conditions $+(.063)$ education means $+(.427)$ organized Planning for education $+(.004)$ traditional approaches of northern areas.

\section{Discussion}

This research focused to investigate the deficiency of higher educational institutes in northern areas of Pakistan and also found the relationship between the dependent variable and independent variables. The result of this quantitative research concludes that the independent variables that are nonexistence availability of higher educational institutions, uncertain economic conditions of northern areas, education means, organized planning for education and traditional approaches of northern areas of Pakistan, effect a lot to promote higher education in northern areas of Pakistan to globalize with the world. Three factors like availability of higher education institutions, uncertain economic conditions of peoples, Organized Planning for education and traditional approaches of northern areas have significant effect to promote higher education in northern areas. According to the results this fourth factor limited means of educational and traditional approaches of northern areas have insignificant effect to Promote higher education in northern areas of Pakistan. Higher education is facing with very severe challenges in the shape of various economic, social, political, and moral changes, and its future depends on the response made by its people to these challenges. Giunchi [29] found that problems plaguing the educational system of Pakistan and South Asian countries are multidimensional like population explosion, lack of resources, nonparticipation of the private sector, scarcity of qualified man power, inconsistency in the policies of various regimes, political instability, inefficient educational management system, wastage of 
resources, and poor implementation of policies and program etc. Gibbons [30] observed Concerning other elements the budget and the allocations made by officers or governing boards among competing demands, the faculty of higher educational institutes should be informed regarding important developments in administrative planning including proposed capital expenditures, and the faculty should also be consulted on major issues of policy involved in such development.

\section{Conclusion}

1. The gender frequency states that 60 percent male and 40 percent female out of 250 samples filling the questionnaire of this research.

2. Table of correlation shows that dependent variable is positively correlated with independent variables. Three variables are significant predictors and two are insignificant predictors out of five.

3. In Model Summary table the value of " $R$ " is .718 which shows the correlation or strength of association is $71.8 \%$ between the independent variables.

4. The value of R Square is .516, which shows that $51.6 \%$ variations subsist on dependent variable due to change in independent variables.

5. The $\mathrm{F}$ Value is 51.939 shows the combine effect of five independent variable of the model.

6. The beta of Nonexistence availability of higher institutions is .161, which shows this variable positively impact on PHE (promote higher education in northern areas of Pakistan) and their impact is significant because sig. value is .001 , which is less than $5 \%$.

7. The beta of uncertain economic conditions is -.113 which indicates the negative impact on PHE and impact is significant because the sig. value is .034, which is less than $5 \%$.

8. The beta of education means is .063 , which shows the positive and insignificant impact on Promotion of higher education in northern areas of Pakistan because their sig. value is .252, which is greater than $5 \%$.

9. The beta of education means is .063 , which shows the positive and insignificant impact on Promotion of higher education in northern areas of Pakistan because their sig. value is .252, which is greater than $5 \%$.

10. The beta of traditional approaches of northern areas is .004, which shows the positive but insignificant impact on Promote higher education in northern areas of Pakistan.

\section{Recommendations}

Government should take the decision to reform the political position of AJ\&K and Northern areas so that they can feel the notable political position in Pakistan. Policy makers should formulate policy to facilitate the local people of northern areas specially $\mathrm{AJ} \& \mathrm{~K}$ by educational development on a big scale. Higher education commission of Pakistan should grant satisfactory funds for educational reformation in the region. It is recommended that opportunities for collaboration with government of Pakistan and well-structured educational strategy should be provided by local administration as well to highlight the deficiency of post graduate programs in northern areas.

\section{References}

[1] Kureshy, K. U., \& Ahmad, K. S. U. A geography of Pakistan. Oxford University Press, USA, 1977.

[2] Fatima, M. Perceptions of geography as a discipline among students of different academic levels in Pakistan. Review of International Geographical Education Online, 6(1), 2016, 67-85.

[3] Stobdan, P., \& Chandran, D. S. The Last Colony: Muzaffarabad-Gilgit-Baltistan. India Research Press, 2008.

[4] Kreutzmann, H. Boundaries and space in Gilgit-Baltistan. Contemporary South Asia, 23(3), 2015, 276-291.

[5] Rasool, G. R. Education in Pakistan: The key issues, problems and the new challenges. IBT JOURNAL OF BUSINESS STUDIES (JBS), 3(1), 2007.

[6] Memon, G. R., Joubish, M. F., \& Khurram, M. A. Education in Pakistan: The key issues, problems and the new challenges. MiddleEast Journal of Scientific Research, 6(6), 2010, 672-677.

[7] Yingyu, Y. A Comparative Study Of Higher Education System In Pakistan And China. Pakistan Journal of Gender Studies, 10(1), 2015, 269-280.

[8] Sales, V. Women teachers and professional development: gender issues in the training 
programmes of the Aga Khan Education Service, Northern Areas, Pakistan. International journal of educational development, 19(6), 1999, 409. 422.

[9] Nazar, A. (2009). Evolution of education in Hunza, the Northern Areas of Pakistan: Views of early teachers of Hunza.

[10]Allen, M. D., \& Allen, M. The goals of universities. Open University Press, 1988.

[11] Malik, S. K., \& Bi, N. B. A study of contribution of Aga Khan Education Services Pakistan for primary education. Asian Social Science, 7(8), 2011, 133.

[12]Rizvi, A., \& Sharif, A. Transforming pedagogy through audio visual aid: An Accomplishment at the Aga Khan University, Karachi. Pakistan Library and Information Science Journal, 50(3), 2019, 19.

[13] University Grants Commission. UGC (Institutions Deemed to be Universities) Regulations, 2010.

[14] Behera, N. C. The Kashmir conflict: multiple fault lines. Journal of Asian Security and International Affairs, 3(1), 2016, 41-63.

[15] Migdal, J. S. Strong societies and weak states: state-society relations and state capabilities in the Third World. Princeton University Press, 1988.

[16] Rehman, A., Jingdong, L., \& Hussain, I. The province-wise literacy rate in Pakistan and its impact on the economy. Pacific Science Review B: Humanities and Social Sciences, 1(3), 2015, 140-144.

[17] Mohanty, J. Current trends in higher education. Deep and Deep Publications, 2000.

[18]Haider, S. Z. Challenges in higher education: Special reference to Pakistan and South Asian developing countries. Nonpartisan education review, 4(2), 2008.

[19] Siddiq, M. K. Pakistan: An educational spectrum. Lahore, Pakistan: Arsalan, 1978.
[20]Fishkin, S. F. Crossroads of Cultures: The Transnational Turn in American Studies-Presidential Address to the American Studies Association, November 12, 2004. American Quarterly, 57(1), 2005, 1757.

[21] Cuthbert, R. Working in Higher Education. Taylor \& Francis, 1900 Frost Road, Suite 101, Bristol, PA, 1996, 19007-1598.

[22] Athiyaman, A. Linking students satisfaction and service quality perceptions: the case of university education. European Journal of Marketing, 31(7), 1997, 528-540.

[23] Dilshad, R. M. Assessing quality of teacher education: A student perspective. Pakistan Journal of Social Sciences, 30(1), 2010, 8597.

[24] Memon, G. R. Education in Pakistan: The Key Issues, Problems and The New Challenges. journal of management and social sciences, 3(1), 2007, 47-55.

[25] Hamidullah, M. comparison of the quality of higher education in public and private sector institutions in Pakistan. PhD, University of Arid Agriculture, Rawalpindi, Pakistan, 2005.

[26] West, A., Noden, P., \& Gosling, R. Qualiy in Higher Education: An International Perspective. London: Centre for Educational Research, 2000.

[27] Teichler, U. Comparative higher education: Potentials and limits. Higher education, 32(4), 1996, 431-465.

[28] Hussain, A., Dogar, A. H., Azeem, M., \& Shakoor, A. Evaluation of curriculum development process. International Journal of Humanities and Social Science, 1(14), 2011, 263-271.

[29] Giunchi, E. Rewriting the past: political imperatives and curricular reform in Pakistan. Internationale Schulbuchforschung, 375-388, 2007.

[30] Gibbons, M. Higher Education Relevance in the 21st Century, 1998.

\section{Creative Commons Attribution License 4.0 (Attribution 4.0 International, CC BY 4.0)}

This article is published under the terms of the Creative Commons Attribution License 4.0 https://creativecommons.org/licenses/by/4.0/deed.en US 